\title{
Implementasi Geolib Pada Peta Lahan Pertanian Untuk Menghitung Luas Dan Batas Lahan Serta Memprediksi Hasil Panen
}

\author{
Septiana Dewi ${ }^{1}$, Ahmad Cucus ${ }^{2}$ \\ Fakultas Ilmu Komputer, Universitas Bandar Lampung \\ J1. Zainal Abidin Pagar Alam No. 26, Labuhan Ratu, Kedaton, 35142, Bandar Lampung, \\ Indonesia. \\ E-mail : \\ Ahmad.cucus@ubl.ac.id \\ septiana.17411073@student.ubl.ac.id
}

\begin{abstract}
ABSTRAKS
Perkembangan teknologi informasi yang sangat pesat tentunya sangat mempengaruhi kehidupan masyarakat di bumi ini. Contohnya di bidang pertanian, teknologi dalam bentuk sistem informasi geografis sangat terasa manfaatnya. Salah satu contoh dari sistem informasi geografis ini adalah peta digital. Peta tersebut dapat menunjukkan wilayah dan atau lahan pertanian dengan menggunakan marker sebagai penanda letak lahan berdasarkan koordinatnya. Selain itu, peta digital juga dapat menampilkan informasi yang berkaitan dengan lahan tersebut. Sebagai salah satunya luas lahan dan berapa prediksi panen pada lahan tersebut. Geolib adalah library javascript yang menyediakan operasi geospasial yang dapat digunakan untuk menghitung luas atau jarak marker pada peta, sedangkan Single Moving Average adalah salah satu metode dalam peramalan yang dapat digunakan untuk memprediksi suatu nilai berdasarkan rata-rata yang bergerak. Dengan menggunakan dua metode ini dalam perancangan peta lahan, maka penulis melakukan langkah-langkah yang dapat menampilkan peta digital yang didalamnya memuat informasi akurat terkait lahan pertanian tersebut.
\end{abstract}

Kata kunci : GIS, Geolib Js, Single Moving Average

\section{PENDAHULUAN}

\subsection{Latar Belakang}

Salah satu penerapan sistem informasi geografis dibidang pertanian yaitu peta lahan pertanian yang tentunya dibuat sacara digital. Peta tersebut dapat dimanfaatkan untuk berbagai kegiatan, mulai dari memetakan hingga mengetahui posisi lahan dalam bentuk visual dan kemudian dapat diakses melalui smartphone, web bahkan aplikasi desktop. Peta tersebut dapat menunjukan suatu wilayah atau lahan pertanian dengan menggunakan marker sebagai penanda letak atau posisi lahan tersebut berdasarkan koordinat tertentu. Selain itu, peta digital dapat menampilkan keterangan atau informasi yang berkaitan dengan lahan pertanian tersebut.

Namun, masalah yang terjadi saat ini adalah adalah peta digital yang sudah ada belum dapat menghitung luas lahan pertanian dan memprediksi hasil panen pada lahan tersebut. Sehingga peta digital tersebut dapat menampilkan informasi dari database secara otomatis. Oleh karena itu, 
penulis mengimplementasikan Geolib pada sistem informasi geografis agar dapat membantu memecahkan masalah di atas.

\subsection{Tujuan}

Adapun tujuan dari peelitian ini adalah menghitung luas dan batas lahan dengan mengimplementasikan Geolib pada peta lahan pertanian serta memprediksi hasil panen secara otomatis menggunakan Single Moving Average pada lahan pertanian tersebut.

\section{TINJAUAN PUSTAKA}

\subsection{Sistem Informasi Geografis}

Sistem informasi geografis atau juga Geographic Information System adalah sebuah sistem yang menyediakan informasi tentang sumber daya lahan yang terkomputerisasi. Berdasarkan tugasnya, sistem informasi memiliki tugas-tugas seperti menginmput, membuat data, memanipulasi data, memanajemen file, menganalisa query serta memvisualisasikan hasilnya. Google Maps API merupakan salah satu teknologi SIG yang sangat populer saat ini. Google Maps API adalah peta dunia yang digunakan untuk melihat suatu daerah menggunakan browser dan layananan ini dapat diakses secara gratis. (Lestari \& Rahardjo, 2016)

\section{$2.2 \quad$ Geolib Js}

Geolib merupakan library dari NPM (Node Package Manager) yang menyediakan operasi geospasial dasar seperti perhitungan jarak, konvensi koordinat decimal ke sexagesimal dan sebaliknya, dan lain-lain. Saat ini, Geolib masih menyediakan perhitungan 2D, artinya ketinggian/elevasi belum didukung oleh salah satu fungsinya. (Schlueter, 2010)

\subsection{Single Moving Average}

Single Moving Average biasa disebut dengan rata-rata bergerak tunggal. Metode tersebut dilakukan dengan mengambil sekelompok nilai pengamatan, mencari rata-ratanya kemudian menggunakan rata-rata tersebut sebagai ramalan untuk periode yang akan datang. (Diploma et al., 2012)

Semakin besar orde rata-rata bergerak, maka semakin besar pula pengaruh pemulusan (Smooting). Rata-rata bergerak berorde T mempunyai karakteristik sebgai berikut :

- Untuk menentukan ramalan pada periode yang akan datang memerlukan data historis selama jangka waktu tertentu. Misalnya, dengan 3 bulan Moving Average, maka ramalan bulan ke-5 baru dibuat setelah bulan ke-4 selesai/berakhir. Jika bulan Moving Average bulan ke-7 baru bisa dibuat setelah bulan ke-6 berakhir.

- Semakin panjang jangka waktu Moving Average, efek smooting semakin terlihat dengan ramalan.

Berikut adalah rumus Single Moving Average :

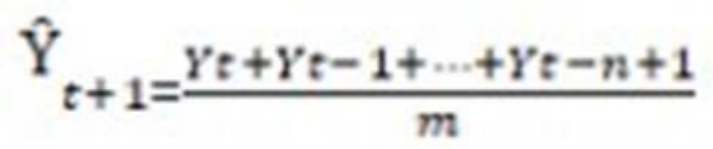




\section{Keterangan :}

Yt +1 : Nilai Ramalan pada periode $(t+1)$

Yt : Nilai sebenarnya / aktual pada periode $\mathrm{t}$

M : Jumlah batas dalam Moving Average

\section{METODOLOGI}

3.1 Metode Eksperimen

Penelitian eksperimen adalah suatu penelitian yang berusaha mencari pengaruh variabel tertentu terhadap variabel yang lain dalanm kondisi yang terkontrol secara ketat. Variabel independennya dimanipulasi oleh peneliti. (Surahman et al., 2016)

\subsection{Metode Pengumpulan Data}

Data yang digunakan dalam penelitian ini yaitu data primer dan sekunder.

\subsubsection{Data Primer}

Metode pengumpulan data primer yang penulis gunakan pada penelitian ini adalah wawancara kepada 20 orang Petani yang berada di Kampung Watu Agung, Kecamatan Kalirejo, tepatnya dusun II, III, V dan IX mengenai jenis lahan sawah, luas lahan sawah, hasil panen permusim yang kemudian akan dicari rata-rata hasil panenya berdasakan luasan lahan untuk digunakan untuk menghitung prediksi hasil panen dimusim berikutnya menggunakan teknik peramalan Single Moving Average.

Adapun daftar pertanyaan yang penulis ajukan untuk mewawancari narasumber antara lain :

- Apakah anda memiliki lahan persawahan?

- Dimana alamat lahan sawah anda?

- Apa jenis lahan sawah anda? (Sawah tadah hujan / irigasi?

- Berapa luas lahan sawah anda?

- Jenis bibit padi apa yang biasa anda tanam?

- Berapa kali panen dalam setahun?

- Berapa jumlah rata-rata panen permusim?

- Faktor-faktor penentu panen/gagal panen? 


\subsection{2}

\subsubsection{Data Sekunder}

Metode pengumpulan data sekunder yang penulis gunakan dalam penelitian ini yaitu dengan melakukan studi Pustaka. Studi Pustaka yang pennulis maksud adalah jurnal-jurnal atau dokumentasi yang telah di publikasikan secraa resmi untuk dijadikan referensi yang tentunya berkaitan dengan penelitian yang penulis lakukan. Referensi tersebut berisikan :

- Geolib-npmjs sebagai penghitung luas Polygon atau area.

- Single Moving Average sebagai metode untuk menghitung prediksi hasil panen lahan persawahan permusimnya.

- MongoDB sebagai database penyimpanan data NoSQL.

- Quasar Framework sebagai pembangun frontend yang interaktif.

- Node Js sebagai pembangun backend sistem ini.

\subsection{Populasi Dan Sampel}

\subsubsection{Populasi Penelitian}

Sesuai dengan masalah penelitian ini, maka yang menjadi populasi pada penelitian ini adalah beberapa Petani di Kampung Watu Agung, Kecamatan Kalirejo, tepatnya dusun II, III, V dan IX, yang jumlahnya 20 orang.

Tabel 3. 1 Populasi Penelitian

\begin{tabular}{|c|c|c|c|c|}
\hline No & Nama Petani & P/L & Dusun & Jenis Sawah \\
\hline $\mathbf{1}$ & Parmuji & L & II & Irigasi \\
\hline $\mathbf{2}$ & Suparmin & L & II & Tadah Hujan \\
\hline $\mathbf{3}$ & Subandi & L & III & Irigasi \\
\hline $\mathbf{4}$ & Sugiyem & L & III & Tadah Hujan \\
\hline $\mathbf{5}$ & Sugino & L & III & Irigasi \\
\hline $\mathbf{6}$ & Marini & P & III & Irigasi \\
\hline $\mathbf{7}$ & Eko Siswanto & L & III & Irigasi \\
\hline $\mathbf{8}$ & Nursandi & L & V & Tadah Hujan \\
\hline $\mathbf{9}$ & Jikan & L & IX & Tadah Hujan \\
\hline $\mathbf{1 0}$ & Saeri & L & IX & Tadah Hujan \\
\hline $\mathbf{1 1}$ & Marmi & P & IX & Tadah Hujan \\
\hline $\mathbf{1 2}$ & Yuyun Yuningsih & P & IX & Tadah Hujan \\
\hline $\mathbf{1 3}$ & Tulus Wijaya & L & IX & Tadah Hujan \\
\hline $\mathbf{1 4}$ & Jumini & P & IX & Tadah Hujan \\
\hline $\mathbf{1 5}$ & Sutarman & L & IX & Tadah Hujan \\
\hline
\end{tabular}




\begin{tabular}{|c|c|c|c|l|}
\hline $\mathbf{1 6}$ & Meludin Himawan & L & IX & Tadah Hujan \\
\hline $\mathbf{1 7}$ & Sri Handayani & P & IX & Tadah Hujan \\
\hline $\mathbf{1 8}$ & Nariyem & P & IX & Tadah Hujan \\
\hline $\mathbf{1 9}$ & Purwati & P & IX & Tadah Hujan \\
\hline $\mathbf{2 0}$ & Mulyono & L & IX & Tadah Hujan \\
\hline
\end{tabular}

\subsubsection{Sampel Penelitian}

Sampel yang penulis gunakan dalam penelitian ini diambil berdasarkan data yang dapat mewakili populasi secara keseluruhan (representatif). Oleh karena populasi penelitian ini jumlahnya kurang dari 100 orang, maka sampel yang penulis gunakan adalah keseluruhan dari jumlah populasi yang menjadi subjek penelitian. Yaitu, 20 orang Petani yang berada di Kampung Watu Agung, Kecamatan Kalirejo, tepatnya dusun II, III, V dan IX.

\subsubsection{Perancangan Desain Sistem}

Dalam penelitian ini, perancangan sistem yang digambarkan adalah perancangan untuk membangun suatu sistem dan mengkonfigurasikan komponen-komponen perangkat lunak dan perangkat keras sehingga menghasilkan kerja sistem yang baik. Tahapan perancangan desain sistem ini akan dijelaskan menggunakan pemodelan sistem informasi berorientasi objek dengan UML.

- Use Case Diagram

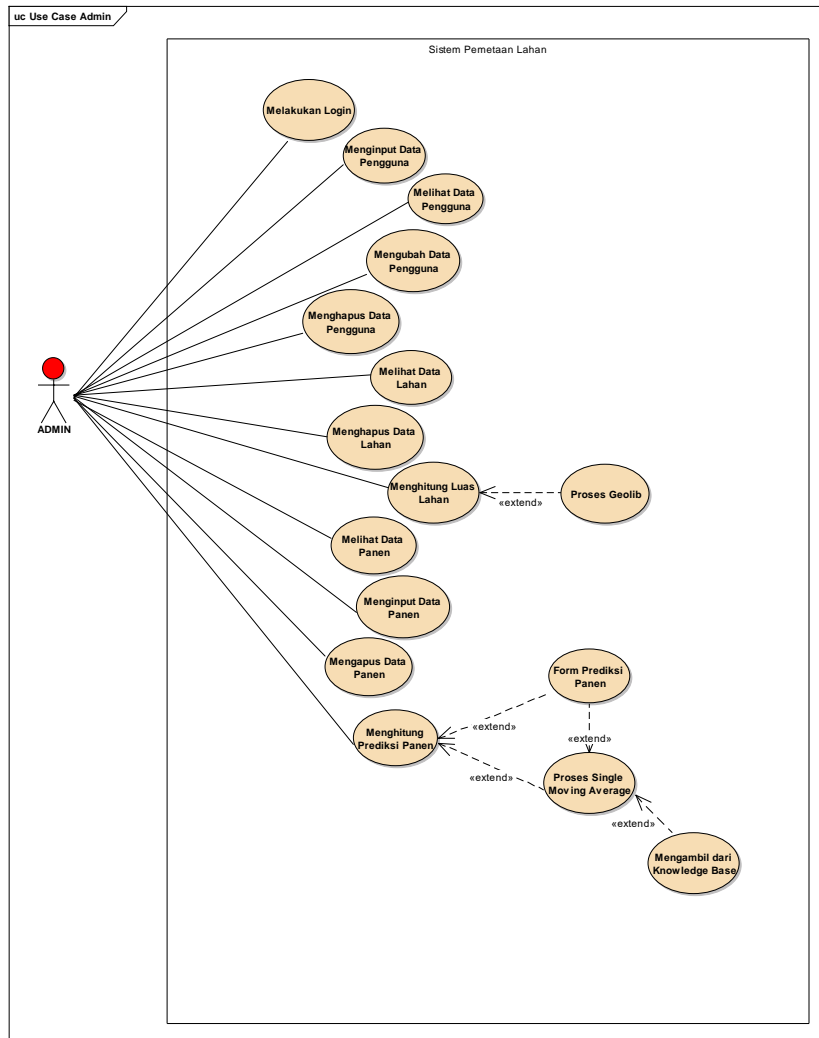




\section{HASIL DAN PEMBAHASAN}

\subsection{Implementasi Geolib untuk Menghitung Luas Polygon}

\subsubsection{Source Code Geolib.js}

Pada tahap ini, sistem akan menghitung luas polygon yang dibentuk oleh titik-titik koordinat yang telah diinputkan petani menggunakan android. Berikut ini source code geolib.js yang fungsinya untuk menghitung luas polygon.

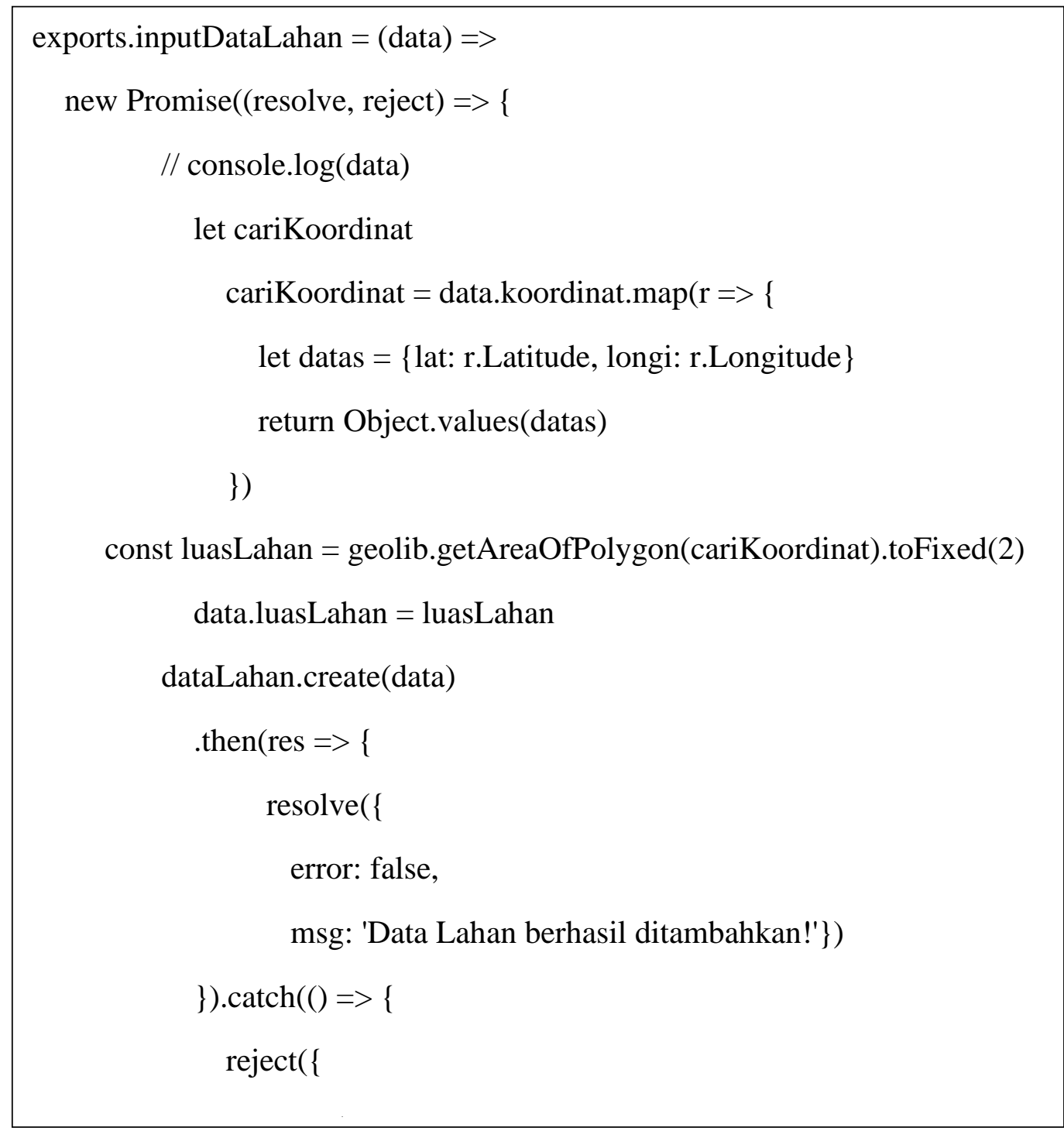

\subsubsection{Hasil Perhitungan Luas Lahan}

Pada perhitungan luas lahan, penulis menggunakan salah satu library javascript yaitu Geolib Js. Geolib akan menghitung luas dari polygon yang dibentuk oleh titik-titik koordinat yang berhasil diinputkan user / petani. Hasil dari perhitungan luas kemudian akan disimpan kedalam tabel Data Lahan di database dan kemudian ditampilkan pada menu data lahan. 


\section{2}

\subsection{Implementasi Single Moving Average untuk Menghitung Prediksi Panen}

\subsubsection{Source Code Single Moving Average}

Pada tahap ini, prediksi hasil panen akan dihitung menggunakan Single Moving Average. Metode ini menggunakan history hasil panen sebelumnya untuk dihitung rata-ratanya kemudian dijadikan prediksi hasil panen masa selanjutnya.

Adapun source code Single Moving Average sebagai berikut :

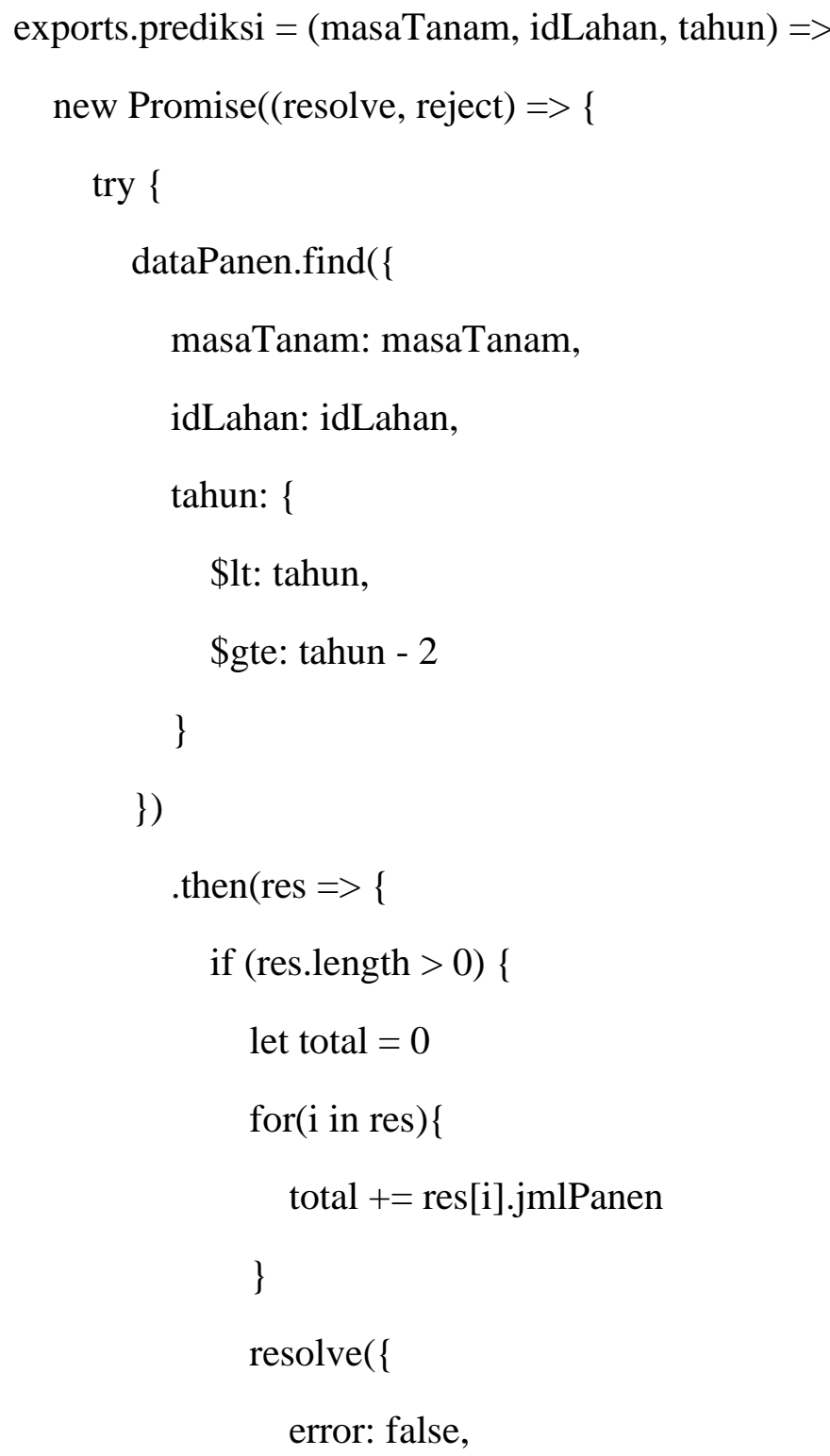





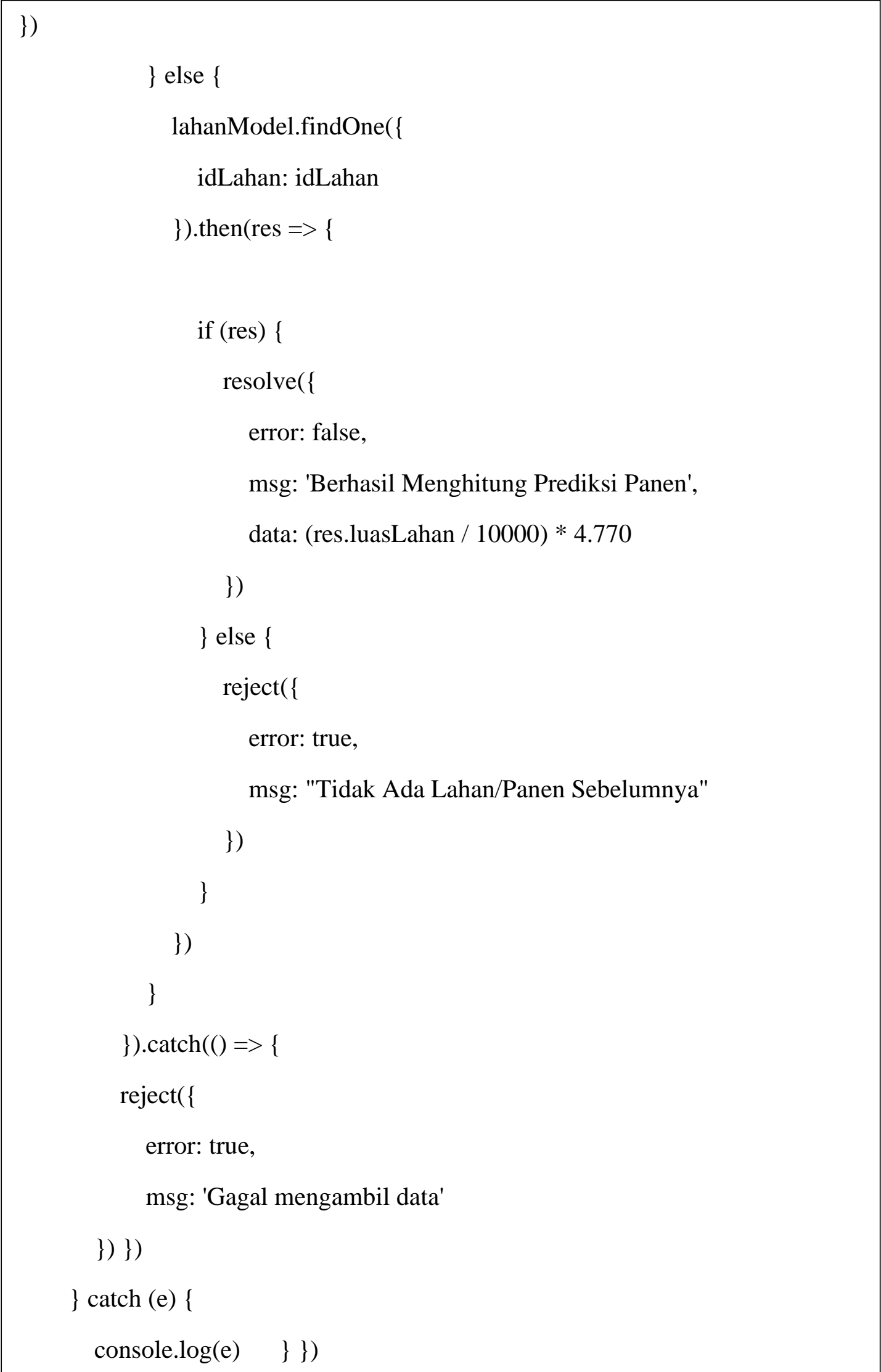


Pada perhitungan prediksi hasil panen ini, apabila lahan yang diprediksi belum memiliki history panen, maka prediksi akan dihitung menggunakan luas lahan di kali rata-rata panen per hektar selama 3 tahun berturut-turut di provinsi Lampung.

\subsubsection{Hasil Perhitungan Prediksi Hasil Panen}

Ada 2 cara yang penulis gunakan untuk menghitung jumlah prediksi panen pada sistem ini, yaitu menggunakan Single Moving Average untuk lahan yang sudah memiliki history panen di tahuntahun sebelumnya dan menggunakan luasan lahan dikalikan rata-rata panen nasional provinsi Lampung untuk lahan yang belum memiliki history panen di tahun-tahun sebelumnya. Berikut ini adalah simulasi perhitungan prediksi jumlah panen pada lahan yang 1001 yang sudah memiliki history panen di tahun-tahun sebelumnya pada masa tanam 1 tahun 2021 menggunakan Single Moving Average di excel.

Tabel 4. 1 Perhitungan Prediksi Panen Menggunakan Ms. Excel

\begin{tabular}{|c|c|c|}
\hline Tahun & Jumlah Panen & SMA \\
\hline 2017 & 4 & \\
\hline 2018 & 4,7 & \#N/A \\
\hline 2019 & 5 & \#N/A \\
\hline 2020 & 4,2 & 4,566666667 \\
\hline 2021 & & 4,633333333 \\
\hline & & \\
\hline
\end{tabular}

Berikut ini adalah simulasi perhitungan prediksi jumlah panen pada masa tanam 1 tahun 2021 untuk lahan 1001 menggunakan Single Moving Average di Sistem Monitoring Lahan.

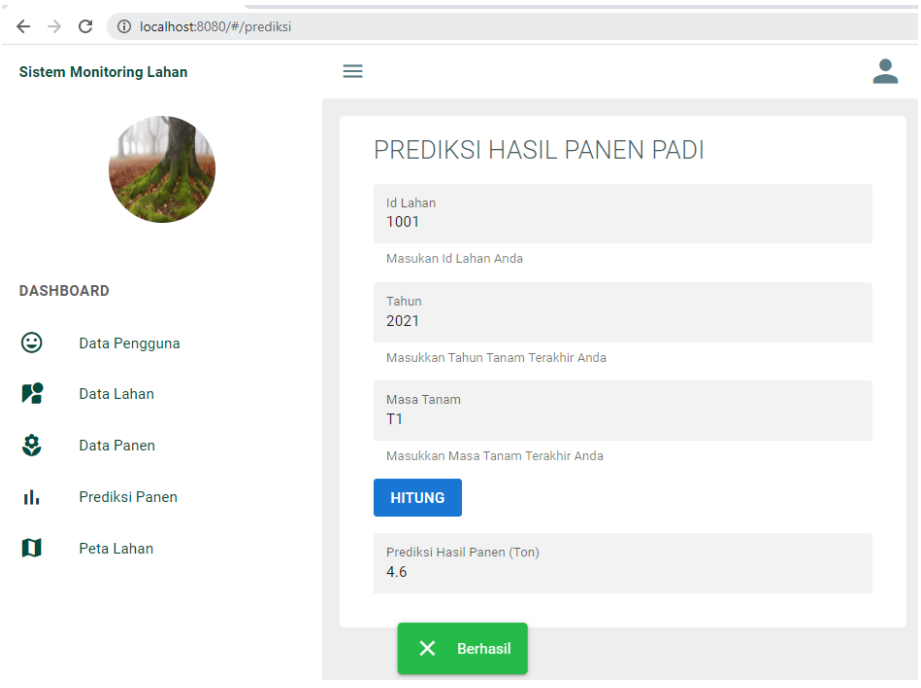

Gambar 4. 1 Perhitungan Prediksi Panen Menggunakan Sistem Monitoring Lahan Untuk Lahan Yang Memiliki History Panen di Tahun Sebelumnya.

Dari kedua gambar diatas, perhitungan prediksi jumlah panen di tahun 2021 untuk masa tanam 1 pada lahan 1001 adalah sekitar 4,6 Ton 
Sedangkan untuk lahan yang belum memiliki history panen di tahun-tahun sebelumnya, maka prediksi hasil panen dihitung berdasarkan luasan lahannya. Adapun rumus yang penulis gunakan yaitu sebagai berikut :

\section{$\operatorname{Pr}=($ luasLahan / 10000$)$ x 4.770}

\section{Keterangan :}

Pr $\quad$ : Prediksi Jumlah Panen

luasLahan : Luasan Lahan Petani $\left(\mathrm{m}^{2}\right)$

$10.000 \quad: 10000 \mathrm{~m}^{2}=1 \mathrm{Ha}$

4.770 : 4,770 Ton ( didapat dari rata-rata panen nasional provinsi Lampung dari tahun 2018 s/d 2020)

Berikut ini adalah perhitungan prediksi jumlah panen pada lahan 1002 yang tidak memiliki history panen di tahun-tahun sebelumnya.

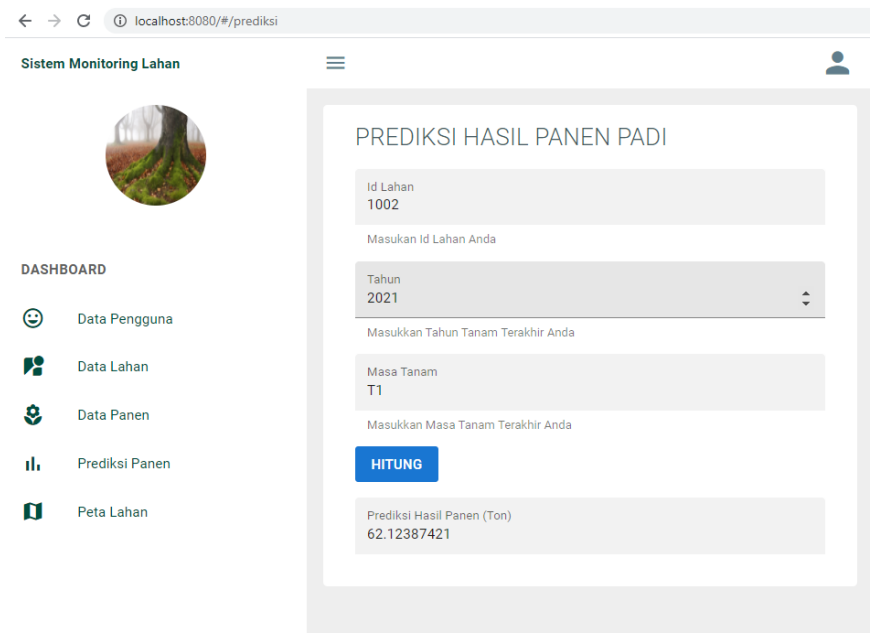

Gambar 4. 2 Perhitungan Prediksi Panen Menggunakan Sistem Monitoring Lahan Untuk Lahan Yang Tidak Memiliki History Panen di Tahun Sebelumnya.

Lahan 1002 memiliki luas 130238,73 $\mathrm{m}^{2}$, dengan rumus diatas maka didapat perhitungan seperti dibawah ini :

$$
\begin{aligned}
\operatorname{Pr} \quad & =(130238,73 / 10000) \times 4.770 \\
& =(13,023873) \times 4.770 \\
& =62,12387421 \text { Ton }
\end{aligned}
$$


Jadi, prediksi jumlah panen pada lahan 1002 pada masa tanam 1 di tahun 2021 adalah sekitar 62,1 Ton.

\section{KESIMPULAN \\ 5.1 Kesimpulan}

Setelah melakukan penelitian ini, dapat penulis simpulkan bahwa :

- Setelah dilakukan pengujian, sistem monitoring lahan ini dapat berjalan di browser dengan baik.

- Sistem Monitoring Lahan ini dapat menghitung luas dan batas lahan menggunakan Geolib $J s$ dan dapat digunakan untuk memprediksi hasil panen menggunakan metode Single Moving Average yang diharapkan mampu membantu petani memonitoring lahan pertanian miliknya secara digital.

\subsection{Saran}

Berdasarkan kesimpulan diatas, maka saran yang dapat penulis sampaikan untuk pengembangan sistem ini selanjutnya adalah Sistem Monitoring Lahan yang berhasil dibuat ini masih sangat jauh dari kriteria sistem yang sempurna, perlu di tambahkan beberapa fitur dan fungsi lagi dalam pengolahan data lahan dan panennya agar semakin mudah dan tepat guna untuk para penggunanya.s

\section{Daftar Pustaka}

Agustian, S., \& Wibowo, H. (2019). Perbandingan Metode Moving Average untuk Prediksi Hasil Produksi Kelapa Sawit. Seminar Nasional Teknologi Informasi, Komunikasi Dan Industri (SNTIKI), 3(2), 156-162.

Diploma, P., Fakultas, I. I. I., \& Maret, U. S. (2012). Penerapan Metode Single Moving Average Dan Metode Exponential Smoothing Pada Peramalan Permintaan Produk Kain Grey Di Pt. Iskandar Indah Printing Textile.

Lestari, S., \& Rahardjo, N. (2016). Desain Visualisasi Profil Data Wilayah Dalam Bentuk Peta Multiskala Di Wilayah Kabupaten Magelang. Jurnal Bumi Indonesia, 5(3), 1-10.

Schlueter, I. Z. (2010). Geolib - npm. Npmjs.Com. https://www.npmjs.com/package/geolib

Surahman, Rachmad, M., \& Supardi, S. (2016). Metodologi Penelitian. In Journal of Materials Processing Technology (Vol. http://dx.doi.org/10.1016/j.cirp.2016.06.001\%0Ahttp://dx.doi.org/10.1016/j.powtec.2016.12. 055\%0Ahttps://doi.org/10.1016/j.ijfatigue.2019.02.006\%0Ahttps://doi.org/10.1016/j.matlet. 2019.04.024\%0Ahttps://doi.org/10.1016/j.matlet.2019.127252\%0Ahttp://dx.doi.o 